\title{
THE PROBLEM OF EXCESSIVE RADIATION DURING ROUTINE INVESTIGATIONS OF THE HEART
}

\author{
BY \\ T. H. HILLS AND R. W. STANFORD \\ From the Diagnostic X-ray Department, Guy's Hospital
}

Received June 27, 1949

Angiocardiography and cardiac catheterization have produced many new problems in radiology, and it is most important that both the cardiologist and radiologist should be aware of the dangers to which they may expose themselves and their patients. For example, in designing apparatus for angiocardiography it must be borne in mind that if this procedure is used for routine investigations care must be taken beyond that necessary in experimental work, since it is essential that all concerned should be adequately protected from both direct and scattered radiation. Unfortunately a knowledge of the output of the X-ray set, in terms of kilovoltage and milliampere seconds, is insufficient to enable the quantity of radiation received by the patient and those in close proximity to the patient to be calculated. In this paper an attempt is made to show what factors must be considered in estimating the direct and scattered X-rays, and to give some indication as to how this estimation can be carried out. Little has been published in the past about the measurement of scattered radiation in diagnostic X-ray work, and the recommendations set out in the following paragraphs are based on experiments carried out in the X-ray Department at Guy's Hospital during investigations of routine cases.

The measurements recorded in the following paragraphs were made with two main objects in view, $(a)$ to ensure that the patient does not receive an excessive dose; and $(b)$ to protect those near to the patient. Whereas the risk to the patient lies in administering a dose of X-rays sufficient to cause burning of the skin, the danger to those nearby arises from the fact that they are frequently exposed to radiation and must be protected from its long-term effects, viz. injury to the superficial tissues, and changes in the blood and bone marrow and reproductive organs. With the average quality of the X-ray beam used for these investigations, that is filtered by one millimetre of aluminium or its equivalent in other ways, the dose that will produce a first-degree erythema of the skin is about 150 rontgen units* delivered on one day. In connection with the filtration of the beam it is useful to note that an aluminium filter is necessary for safety and such a filter or its equivalent is frequently incorporated during manufacture. The purpose of this is to suppress the very soft radiation from the tube since such radiation is particularly harmful. The filter does not eliminate the risk of burning referred to previously, nor does it give any indication of the dosage. The maximum permissible whole body dose for persons who are regularly exposed to radiation, such as the radiologist, surgeon, and anæsthetist, has been fixed as $0.5 \mathrm{r}$. per week, or a dosage rate of $4 \times 10^{-6} \mathrm{r}$. per second. For the hands, informed opinion tentatively regards $1.5 \mathrm{r}$. per week as the maximum permissible dose. At the outset we wish to emphasize the fact that although these investigations are diagnostic procedures nevertheless it is quite possible for the patient to receive a dose sufficient to cause a first-degree erythema and for those nearby to receive a dose well in excess of the permitted maximum. Further-

* The rontgen (r.-unit) is a unit of dosage for ionizing radiations and is based on the ionization produced by the radiation in air under standard conditions.

In this paper the abbreviation $r$. denotes rontgen. 
more the potential injury is caused to the patient by the direct beam; but to those nearby, mainly by radiation scattered from the patient.

The arrangement of apparatus employed for routine cases of angiocardiography has already been described by Hills (1948), and that for cardiac catheterization by Holling and Zak (1950). Using these methods, observations have been made both during treatment of patients and by using a wax phantom to simulate the patient. For the determination of doses the instruments used were a Victoreen dosemeter, a pocket type Lauritsen dosemeter, and a small condenser ionization chamber with a Baldwin Farmer electrometer. A Philips D.X.4 set was used for angiocardiography and a G.E. Victor set for the catheterization.

\section{ANGIOCARDIOGRAPHY}

Fig. 1 shows the relative positions of patient, tube and camera. Points $\mathrm{X}$ and $\mathrm{Y}$ indicate the approximate positions of the surgeon and anæsthetist.

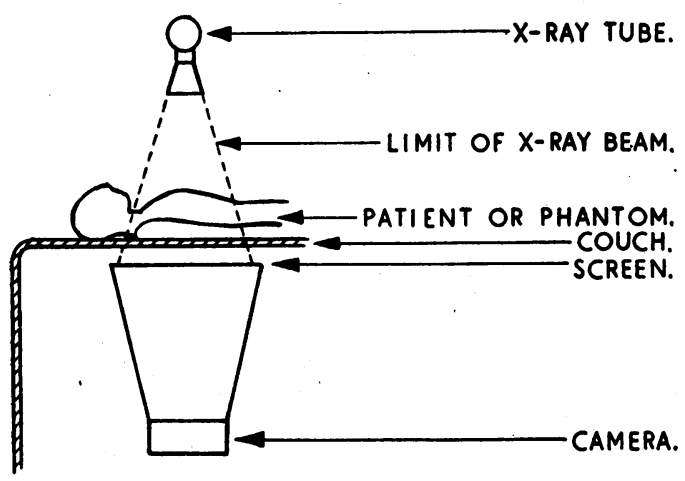

A

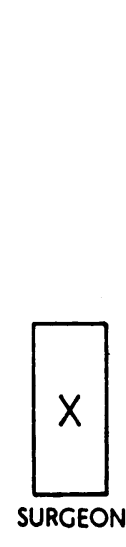

SURGEON

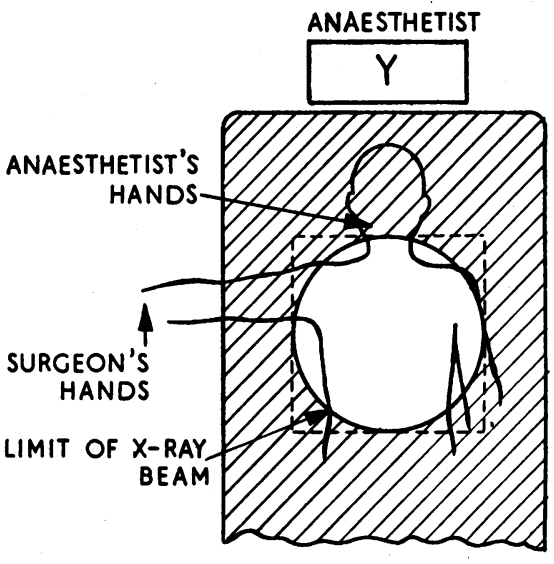

B

FIG. 1.-Diagrams of position of patient, tube and camera and the relative positions of surgeon and anæsthetist. (A) Side view. (B) Plan view.

A short focus screen distance was largely dictated by the need for obtaining the brightest shadow on the screen, and in practice this distance was set for 30 inches. It was of course arranged that the X-ray beam should cover only the area of the fluorescent screen that was photographed by the camera. The settings for the tube were generally in the range 70-77.5 kilovolts, 300-400 milliamperes, and $0 \cdot 1$ seconds for A.P. views. For oblique views the kilovoltage was increased to 80-85. For the purpose of taking measurements the settings (nominal) employed were $77 \cdot 5$ kilovolts, 400 milliamperes, and 0.1 seconds.

The radiation dose at the level of the skin of the patient, but without a patient in position, was found to be $1 \cdot 1 \mathrm{r}$. per exposure. When a wax phantom was inserted in the position which would be occupied by the patient the dose was $1.5 \mathrm{r}$. per exposure. This difference is due to the fact that when the direct beam enters the phantom (or patient) some of the radiation is scattered. A proportion of this radiation is scattered back towards the tube and emerges at the surface of the phantom (or patient) where it reinforces the direct beam. The total dose at the surface thus comprises incident plus scattered radiation and is termed the "skin dose." Over the whole irradiated surface this skin dose varies from $1.0 \mathrm{r}$. at the perimeter of the field to $1.5 \mathrm{r}$. at the centre. Thus the average skin dose per exposure may be taken as $1.3 \mathrm{r}$.

Observations of scattered radiation were made at various points in space round the phantom. For convenience the values quoted are those showing the variation $(a)$ along the horizontal direction. coinciding with the outstretched arm of the patient, $(b)$ along the vertical directions at a distance 
corresponding with the approximate position of the surgeon, and $(c)$ along the vertical direction at a distance corresponding with the approximate position of the anæsthetist. These are summarized in Table I.

TABLE I

Scattered Radiation at Various Points Round the Patient

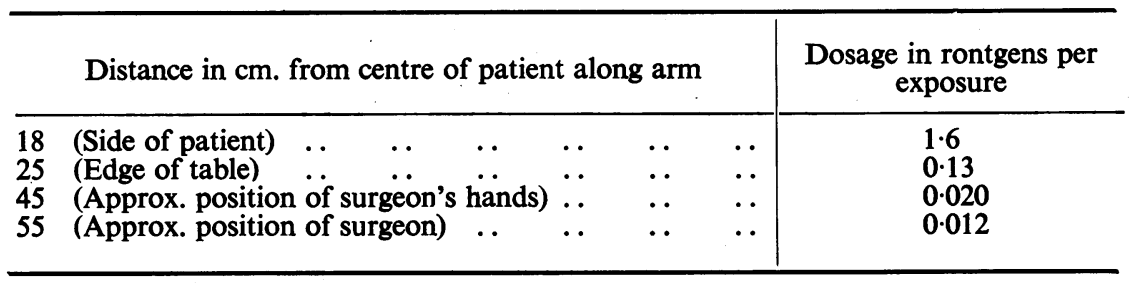

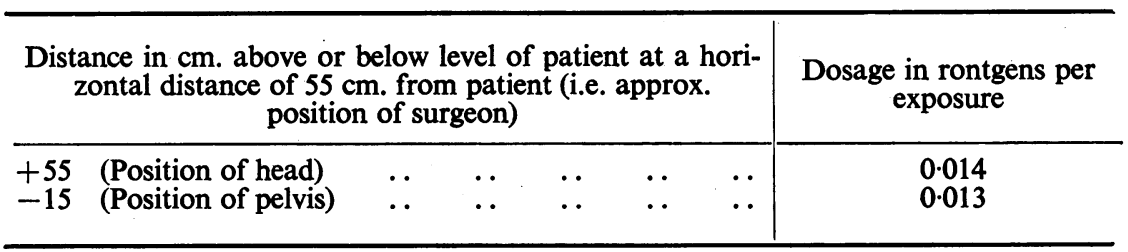

\begin{tabular}{|c|c|c|c|c|c|c|c|}
\hline \multicolumn{7}{|c|}{$\begin{array}{l}\text { Distance in } \mathrm{cm} \text {. above or below level of patient at a } \\
\text { horizontal distance of } 40 \mathrm{~cm} \text {. from patient (i.e. approx. } \\
\text { position of anæsthetist) }\end{array}$} & \multirow{2}{*}{$\begin{array}{c}\begin{array}{c}\text { Dosage in rontgens per } \\
\text { exposure }\end{array} \\
\begin{array}{c}0.025 \\
0.027\end{array}\end{array}$} \\
\hline $\begin{array}{r}20 \\
-40\end{array}$ & $\begin{array}{l}\text { (Position of head) } \\
\text { (Position of pelvis) }\end{array}$ & $\ddot{m}$ & $\ddot{x}$ & $\ddot{*}$ & $\ddot{~}$ & $\begin{array}{l}\ldots \\
\ldots\end{array}$ & \\
\hline
\end{tabular}

During the course of a number of investigations a small condenser chamber was placed inside the surgeon's glove to record the dose received at the back of his hand. These readings varied from $0.1 \mathrm{r}$. to $1.0 \mathrm{r}$. for a complete series of exposures, the most frequent value being $0.2 \mathrm{r}$. The dose was closely related to the size of the patient and hence to the distance of the hand from the patient (see Table I). Measurements were also made to determine the dose received by the anæsthetist's hands, the position of which depends on the size of the patient. In practice only young patients are anæsthetized and of necessity the hands are always on the fringe of the direct beam and frequently directly in the beam. Observations showed that the dose received by the back of the hands could vary from $0.82 \mathrm{r}$. on the fringe of the beam to $1.5 \mathrm{r}$. in the beam, per exposure. This latter dose is greater than that received by the patient because the hands are closer to the tube.

All the doses quoted above will vary if kilovoltage, tube current, and/or exposure time varies. The effects of such variations are shown in Table II. It will be noted that the exposure time was fixed at $0 \cdot 1$ seconds since experience showed that this was the optimum time to reduce the blurring due to respiration and still achieve adequate contrast on the films.

Changes in kilovoltage and tube current are made in order to compensate for the variation in size of the patient. Consideration of these figures reveals that the intensity of the scattered radiation does not vary significantly with changes in size of the patient.

\section{Cardiac Catheterization}

The problem to be considered in this case differed from the previous one in so far as the patient is screened, using the under-couch tube, at a lower kilovoltage and a very much smaller tube current but for a greatly increased length of time. The arrangement of apparatus admits of less variation 
TABLE II

Variation of Dosage with Change of Kilovoltage and Tube Current

\begin{tabular}{|c|c|c|c|c|c|c|c|c|c|}
\hline \multirow{3}{*}{ Kilovolts } & \multirow{3}{*}{$\begin{array}{l}\text { Tube } \\
\text { current in } \\
\text { milli- } \\
\text { amperes }\end{array}$} & \multirow{3}{*}{$\begin{array}{l}\text { Exposure } \\
\text { time in } \\
\text { seconds }\end{array}$} & \multicolumn{7}{|c|}{ Dosage per exposure, in rontgens, to } \\
\hline & & & \multicolumn{3}{|c|}{ Surgeon } & \multirow{2}{*}{$\begin{array}{l}\text { Patient. Skin } \\
\text { dosage at centre } \\
\text { of field }\end{array}$} & \multicolumn{3}{|c|}{ Anæsthetist } \\
\hline & & & hands & head & pelvis & & hands & head & pelvis \\
\hline $\begin{array}{l}77.5 \\
70.0 \\
82.5 \\
77.5 \\
70.0 \\
82.5\end{array}$ & $\begin{array}{l}400 \\
400 \\
400 \\
300 \\
300 \\
300\end{array}$ & $\begin{array}{l}0 \cdot 1 \\
0 \cdot 1 \\
0 \cdot 1 \\
0 \cdot 1 \\
0 \cdot 1 \\
0 \cdot 1\end{array}$ & 0.02 & 0.014 & $\begin{array}{l}0.013 \\
0.012 \\
0.015 \\
0.010 \\
0.008 \\
0.012\end{array}$ & $\begin{array}{l}1.5 \\
1.3 \\
1 \cdot 7 \\
1 \cdot 1 \\
1.0 \\
1 \cdot 1\end{array}$ & $\begin{array}{l}1.5 \\
\text { to } \\
0.82\end{array}$ & 0.015 & $\begin{array}{l}0.027 \\
0.026 \\
0.030 \\
0.012 \\
0.016 \\
0.026\end{array}$ \\
\hline
\end{tabular}

than for angiocardiography, and in fact the only factor directly controlled by those taking part in the investigation is the position of the diaphragms of the tube. This will be referred to later in the paper.

Before making observations it was necessary to decide on suitable settings for the tube. A time limit of twenty minutes had already been imposed on the grounds of possible harm to the patient, and experience had shown that the screening current could be much reduced whilst still maintaining a suitable contrast on the screen. Nominal settings of 64 kilovolts and 0.5 milliamperes were used for the bulk of the observations. Although the screening current is quoted as 0.5 milliamperes, it must be understood that for purely technical reasons the actual current through the tube differs from this by an amount depending on the particular set used (see later paragraph). In addition the diaphragms were closed down as far as possible, the screen itself being moved when necessary to follow the movements of the catheter. The measured area of cross-section of the beam on the back of the patient was about $12 \mathrm{~cm}$. by $12 \mathrm{~cm}$. For the majority of measurements a wax phantom was used, the phantom being placed about $1.5 \mathrm{~cm}$. above the surface of the couch to allow for the fact that the patient normally rests on a sorbo rubber pad on the couch.

The first observations were to determine the skin dose to the patient. Using 64 kilovolts and 0.5 milliamperes the measured dose rate at the skin was $5.5 \mathrm{r}$. per minute. This value varies markedly with change of kilovoltage or tube current as can be seen from Table III.

TABLE III

Skin Dose of Radiation with Different Screening CurRents

\begin{tabular}{c|r|r|r|r|r}
\hline \multirow{2}{*}{ Kilovolts } & \multicolumn{3}{|c}{$\begin{array}{c}\text { Dosage rate at the skin, expressed in rontgens per minute, for } \\
\text { nominal screening currents, expressed in milliamperes, of }\end{array}$} \\
\cline { 2 - 5 } & 0.5 & 1.0 & 1.5 & 2.0 & 2.5 \\
\hline 52 & 3.6 & 5.2 & 7.0 & 8.0 & 9.0 \\
64 & 5.5 & 8.5 & 11.0 & 13.5 & 15.0 \\
76 & 7.0 & 11.0 & 15.0 & 18.5 & 21.0 \\
88 & 8.2 & 13.5 & 18.6 & 22.6 & 27.0 \\
\hline
\end{tabular}

At this point is is necessary to emphasize certain aspects of these data. On the set in use, and in fact or many diagnostic sets, it is not easy to adjust the tube current accurately to 0.5 milliamperes. Further, when the meter reads between 0 and 3.0 milliamperes the registered value cannot be taken as the precise current through the tube. For the apparatus used in these experiments it was possible 
to check the actual tube current by putting a meter in the high voltage lead to the anode and comparing its readings with those registered at the control panel. These observations showed that when the control panel meter registered 0.5 milliamperes, i.e. the nominal setting referred to in Table III, the current through the tube was 0.9 milliamperes.

The significance of these facts is that the dosage rates given above, whilst true for the particular equipment, will not necessarily be true for another equipment set up to the same nominal readings of kilovoltage and tube current. An additional factor that will have an effect on output is the inherent filtration of the tube, i.e. the filtering of the radiation from the anode by the walls of the tube and by any other material placed in the path of the beam. When a tube ages, metal from the anode is deposited on the inside of the walls of the tube, and the anode becomes pitted. Both these effects increase the inherent filtration, thus reducing the output. As an example of these factors the output of a tube of identical manufacture but much older and fitted to another equipment with a different control desk was measured. The conditions as far as tube-phantom distance, aperture of beam, etc., were concerned were the same, and the control desk was set to give 64 kilovolts, 0.5 milliamperes as nearly as possible with the controls provided. The dosage rate at the skin was measured as $1.7 \mathrm{r}$. per minute which is appreciably less than that obtained with the set normally used. Finally, it must be borne in mind that the intensity of X-rays falls off inversely as the square of the distance from the source. The focus-skin distance in the apparatus employed was approximately $40 \mathrm{~cm}$. If this distance were increased to $80 \mathrm{~cm}$. then the tube output would need to be increased fourfold in order to obtain the same brightness at the screen as is used in routine work.

Clearly the criterion to be adopted in deciding upon a suitable setting of kilovolts and tube current must be related to the contrast on the fluorescent screen. In this connection the relative opacity of the catheter is important. For routine investigations at Guy's the catheters used are of American manufacture and have an opaque tip. Other types of catheter may be more or less opaque and will necessitate a suitable adjustment of the tube output. Whatever type of catheter is used, the aim must be to work with the minimum screening current that will suffice to give an adequate degree of contrast on the screen, thus enabling the position of the catheter to be established without ambiguity. The observer must be thoroughly dark-adapted before attempting to judge the suitability of the contrast on the screen.
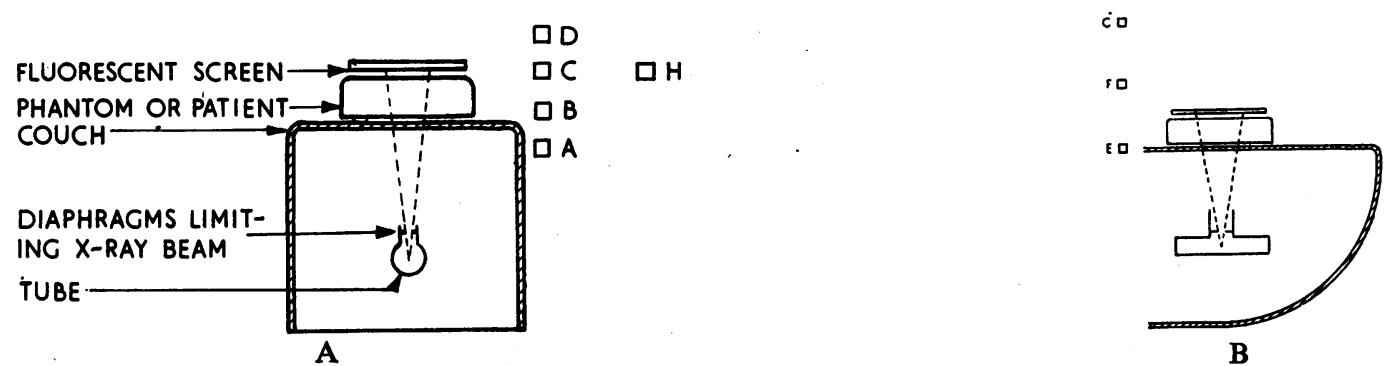

Fig. 2.-Diagram of screen, patient, and X-ray tube with the points marked at which scattered radiation was measured.

(A) End view. For A, B, C, D, and $\mathrm{H}$ see text and Table IV. (B) Side view. For E, F, and G see text and Table IV.

The measurements made on scattered radiation were carried out in the same manner as for angiocardiography. In this case a fluorescent screen is placed immediately above the patient and this affords a substantial measure of protection in the region of the shadow cast by this screen. The diaphragms are closed as far as possible and this, together with the fact that the lead glass on top of the screen is equivalent to $1.5 \mathrm{~mm}$. of lead under the conditions employed, reduces the radiation passing through the screen to negligible proportions. However, it has been found convenient to use quite a small screen so that the region in space from which radiation is blotted out by the screen is smaller than it would normally be. The results are given in Table IV and the points at which measurements were made are related to Fig. 2 by letters. 
To illustrate the reduction in dose rate brought about by increase in distance from the patient, the observation of dose at the level of the surgeon's hands was repeated at a point $20 \mathrm{~cm}$. farther away (see point $\mathrm{H}$ in Fig. 2). This point was a total distance of $50 \mathrm{~cm}$. from the centre of the field, and was in the approximate position of the surgeon. At 0.5 milliamperes the dosage rate was $0.003 \mathrm{r}$. per minute and for 1.0 milliamperes it was $0.0045 \mathrm{r}$. per minute, a reduction of some 50 per cent from the dosage rate at point $\mathrm{C}$.

\section{TABLE IV}

Measurement of Scattered Radiation at Different LeVels

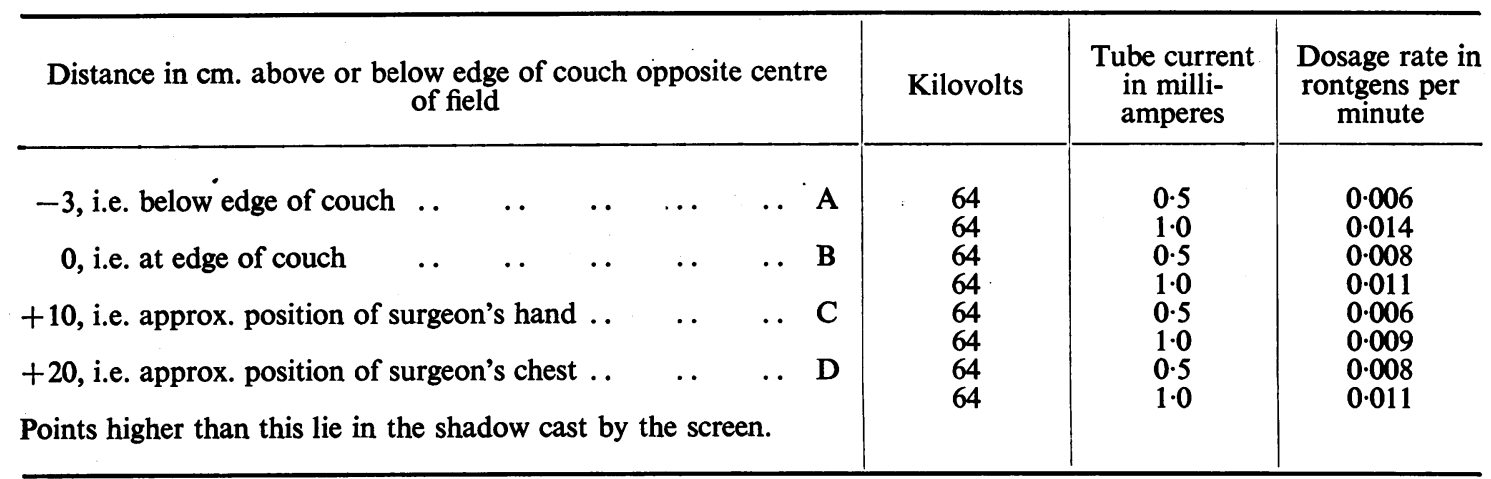

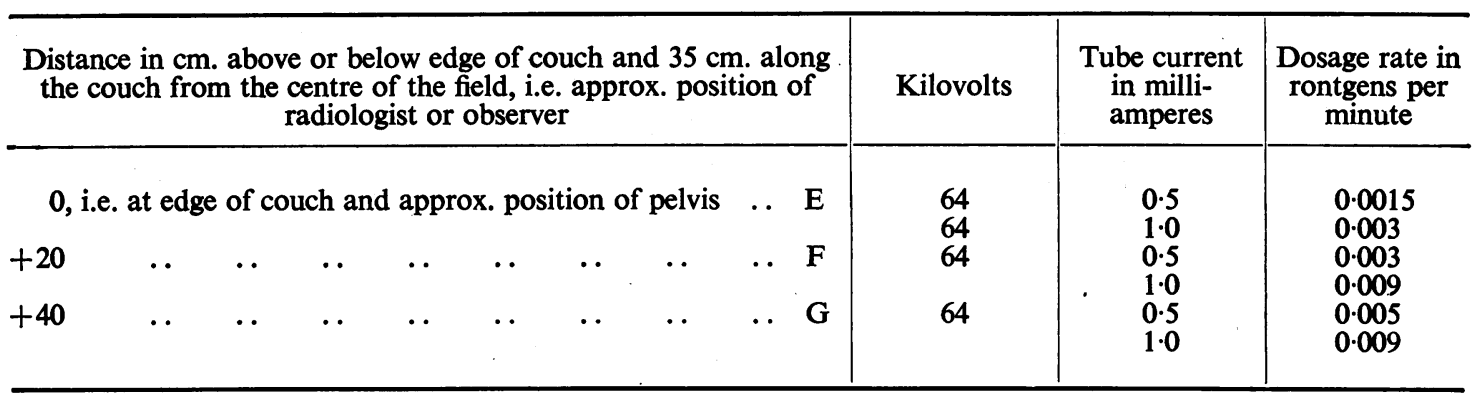

Any increase in the area of the patient's skin that is irradiated will give rise to two effects. The first of these is that there will be an increase in the skin dose and in the area of the skin affected, the second is that there will be an increase in the intensity of scattered radiation. As an illustration of these effects three measurements were repeated, the skin dosage rate to the patient at 64 kilovolts and 0.5 milliamperes, the intensity of scattered radiation at the position corresponding to the surgeon's hands, and the intensity of scattered radiation at a point corresponding to the surgeon's body, all being taken with the irradiation area increased fourfold. The respective values were 7.2 $\mathrm{r}$. per minute, $0.06 \mathrm{r}$. per minute, and $0.02 \mathrm{r}$. per minute, representing a substantial increase.

Observations were taken of the skin dose to the patient and the dose to the surgeon's hands during several catheterizations. These values are in fair accord with the results quoted above, but the measured skin dose is likely to be smaller than that given in the previous paragraph. The reason for this is simply that it is impossible to move the dose measuring chamber about beneath the patient to follow the movements of the screen, and further, the position of the chamber must be at the edge of the field in order to avoid causing any interference with the picture on the screen. The doses given are therefore likely to be smaller than the actual dose received by the patient's skin. In contrast to this it can be seen that the dose to the surgeon's hand is greater than expected; this is almost certainly due to the hand being closer to the patient. 
TABLE V

Skin Dose to the Patient and to the Surgeon's Hands during Cardiac Catheterization

\begin{tabular}{|c|c|c|c|c|c|}
\hline Patient & $\begin{array}{l}\text { Nominal } \\
\text { kilovolts }\end{array}$ & $\begin{array}{l}\text { Nominal tube } \\
\text { current in milli- } \\
\text { amperes }\end{array}$ & $\begin{array}{l}\text { Screening time } \\
\text { in minutes }\end{array}$ & $\begin{array}{l}\text { Skin dose in } \\
\text { rontgens }\end{array}$ & $\begin{array}{l}\text { Dose to surgeon's } \\
\text { hands in rontgens }\end{array}$ \\
\hline \multirow[t]{2}{*}{$\begin{array}{l}\text { A } \\
\text { B } \\
\text { C } \\
\text { D }\end{array}$} & $\begin{array}{l}62 \\
62 \\
64 \\
64\end{array}$ & $\begin{array}{l}0.5 \\
0.3 \\
0.3 \\
0.5\end{array}$ & $\begin{array}{l}15 \frac{1}{2} \\
15 \frac{1}{2} \\
5 \\
20\end{array}$ & $\begin{array}{l}86 \\
50^{*} \\
34 \\
77\end{array}$ & $\begin{array}{l}0.22 \\
0.65 \\
0.22 \\
0.47\end{array}$ \\
\hline & \multicolumn{4}{|c|}{ * Measuring instrument at extreme edge of field. } & \\
\hline
\end{tabular}

\section{Chest Radiographs}

Skin doses were measured for twenty patients using a 6-ft. focus-film distance. With ordinary film the variation was from $0.13 \mathrm{r}$. to $0.22 \mathrm{r}$, whilst with special fast film a smaller dose varying from 0.04 r. to 0.12 r. was measured.

\section{ROUTINE SCREENING}

The considerations outlined for catheterization in respect of variation in tube output, variation of skin dose with kilovoltage, tube current and screening time, effects of aperture of the diaphragms and focal skin distance and the variation of scattered radiation apply equally in this case. There are, however, certain differences worthy of notice. In a general investigation of this type it is frequently necessary to work with the diaphragms set so as to cover the whole chest instead of a part of it. A brighter screen, requiring a larger tube current is often needed, but the screening time is normally much less than that for catheterization. Observations showed that using a Philips D.X.4 set at 60 kilovolts and 1.5 milliamperes with a focus screen distance of $80 \mathrm{~cm}$., the skin dosage for an average screening time of $3 \frac{1}{2}$ minutes was $7 \cdot 7 \mathrm{r}$.

\section{DisCUSSION}

In assessing the value of these measurements it must be remembered that the observations are certainly not more accurate than \pm 10 per cent, and in particular that measurements made on one $\mathrm{X}$-ray set are not immediately applicable to another. Nevertheless, the figures quoted do give the correct order of magnitude of the doses, and the conclusions drawn from them do indicate the precautions most likely to be needed to protect the patient and those nearby. It is convenient to review these figures in terms of the patient and those nearby under separate headings.

Patient. There is a risk that he may receive a skin dose sufficient to produce some degree of $\mathrm{X}$-ray burning. It is not thought likely that the total radiation will have any harmful effect otherwise. In considering the effect of X-rays on the skin the time factor must not be omitted, and in assessing the total skin dose all $\mathrm{X}$-ray investigations made must be taken into account since the effects are cumulative. The whole investigation may include ordinary chest films taken at six feet, screening and a barium swallow (probably with further films), screening and further films with cardiac catheterization and an angiocardiography series. The doses on the skin during these investigations are shown in Table VI.

It is obvious that as a diagnostic X-ray procedure one should not approach a skin erythema dose. If a patient has received a dose in the nature of $150 \mathrm{r}$. he should certainly not have any further radiation to the same area for a period of at least 14 days, and in any year should not receive such a dose on more than three or four occasions at most. Although the tube current for fluoroscopy is fractional in comparison with that used for individual angiocardiographs this aspect of the subject is of no less importance, since it is clear that the greatest dose is that administered during screening. 
It is therefore very necessary to decide upon the maximum safe screening time. The most satisfactory method of doing this is to measure the skin dosage rate to the patient under the conditions obtaining during the investigation, and so determine the time during which a dose of $150 \mathrm{r}$. would be administered. Failing this, it is possible to arrive at an order of magnitude for the skin dosage rate by making use of published data (Binks, 1943) for tube outputs and by assuming that the actual dose at the skin will be increased by a factor of about 20 per cent as a result of back scatter. Hence, again, the maximum safe screening time can be determined. In practice it may well be that the time taken by cardiac catheterization, and therefore the skin dose to the patient, are less than the maximum. If this reduction in dose is appreciable then the time that should elapse before angiocardiography can also be reduced, the extent of the reduction being determined by the actual dose received.

TABLE VI

Summary of Skin Dosage to the Patient

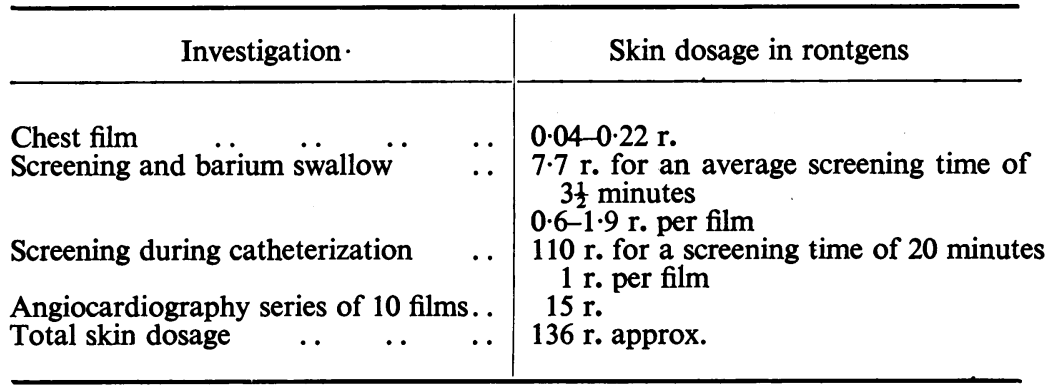

Those in close proximity to the patient, i.e. surgeon, ancesthetist, and radiologist. The danger incurred by those assisting lies in the regular exposure to radiation. From the figures already given typical whole body doses and hand doses are shown in Table VII.

TABLE VII

Summary of Dosage to Surgeon, Anasthetist, and Radiologist

\begin{tabular}{|c|c|c|c|}
\hline Investigation & & & Dosage \\
\hline $\begin{array}{l}\text { Catheterization , .. } \\
\text { Angiocardiorgaphy .. }\end{array}$ & $\cdots$ & $\begin{array}{l}\text { Surgeon-hands } \\
\text { Surgeon-whole body } \\
\text { Radiologist-whole body } \\
\text { Surgeon-hands } \\
\text { Surgeon-whole body } \\
\text { Anæsthetist-hands } \\
\text { Anæsthetist-whole body }\end{array}$ & $\begin{array}{l}0.12 \mathrm{r} . \text { for } 20 \text { minutes } \\
0 \cdot 16 \mathrm{r} \text {. for } 20 \text { minutes } \\
0 \cdot 16-0.60 \mathrm{r} \text {. for } 20 \text { minutes (depending on } \\
\text { position) } \\
0 \cdot 20 \mathrm{r} \text {. for } 10 \text { films } \\
0 \cdot 13 \mathrm{r} \text {. for } 10 \text { films } \\
8 \cdot 2-15 \mathrm{r} \text {. for } 10 \text { films (depending on } \\
\text { position) } \\
0 \cdot 27 \mathrm{r} \text {. for } 10 \text { films }\end{array}$ \\
\hline
\end{tabular}

The above figures refer to one investigation: if the same person carries out more than one a week the dose will increase proportionately.

It will be clear from these figures that the intensity of the scattered radiation is by no means negligible. In fact for the anæsthetist in angiocardiography it is far in excess of the permitted dose, and may easily become so for the surgeon, especially if his hands move into the direct beam. Further, if the same surgeon does two or three investigations a week he then receives a dose 
approaching the maximum. Precautions must be taken to ensure safety, and this can be achieved in three ways:

(a) by increasing the distance from the source of radiation, i.e. making use of the fact that the intensity falls off as the inverse square of the distance,

(b) by the use of protective clothing,

(c) by employing lead, lead glass, or lead rubber screening.

From (a) it follows that all those concerned should be as far as possible from the table. During catheterization the surgeon and radiologist must be very close to the table and can make little or no use of this factor and must rely on other measures. In angiocardiography the position of the anæsthetist is. fixed and he too must rely on other protective measures. On the other hand the surgeon can have the patient's arm outstretched and by using a syringe with a long cannula can stand so that his body is $50-60 \mathrm{~cm}$. from the centre of the patient and his hands well out of the direct beam during the actual exposures.

Considering $(b)$ it is clear that the surgeon can wear a lead rubber apron, but some form of special glove may have to be devised since it is impossible to make an injection or insert a cardiac catheter whilst wearing lead rubber gloves. In angiocardiography the anæsthetist should undoubtedly wear lead rubber gloves and a lead rubber apron. Experience has shown that the use of lead rubber gloves for the 10 or 15 seconds of the exposures, whilst causing some inconvenience, does not seriously impair the anæsthetist's efficiency. During catheterization the radiologist should wear a lead rubber apron but can dispense with gloves, since his hands are usually resting on, and hence protected by, the screen.

With regard to $(c)$, this presents certain difficulties but they are not insuperable and the use of permanent or detachable protective screens has much to commend it since, if suitably designed, they may obviate the necessity for wearing protective clothing. For angiocardiography such protection for the surgeon is quite feasible and could take the form of lead sheet, or lead rubber below the level of the patient, and lead glass, with an aperture for the patient's arm, above the level of the patient. Similarly, the lower part of the anæsthetist's body could be protected, although it is doubtful whether it would be possible to devise suitable screening for the hands and upper part of the body. During catheterization the problem is not quite so simple. Lead rubber can be hung from the screen, but as the screen may well be moved about over the patient this may cause a measure of discomfort to the patient which cannot be tolerated for 20 minutes. Again, a protective screen over the patient's arm may well cause considerable inconvenience to the surgeon and discomfort to the patient. On the whole it is probably better to rely on personal protection in this case and reduce the risk by cutting down the screening current as far as possible and limiting the number of catheterizations-carried out each week by the same surgeon so as to bring the dose to the hands within the permitted tolerance.

\section{SUMMARY}

An account of measurements made during routine cases of angiocardiography and cardiac catheterization is given. Details of the possible doses to patient and those assisting in the treatment are computed and suggestions made as to means whereby these doses can be kept within the permitted maximum doses.

Binks, W. (1943). Brit. J. Radiol., 16, 49.

\section{REFERENCES}

British Medical Bulletin, Vol. 4, No. 1, 1946.

Ellis, F. (1948). Brit. J. Radiol., 21, 1.

Hills, T. H. (1948). Ibid., 21, 511.

Holling, H. E., and Zak, G. (1950). Brit. Heart J. (in the press, April, 1950)

Recommendation of the British X-ray and Radium Protection Committee. 7th Revised Report (October 1948).

Sievert, R. M. (1947). Brit. J. Radiol., 20, 306. 